\title{
The Therapy of Burn Wound Healing in Rat (Wistar) by Using the Combination of Peripheral Blood Mononuclear Cells (PBMCs) and Bone Marroe BM-Derived Mesenchymal Stem Cell
}

\author{
Gusti Revilla $^{1 *}$, Eryati Darwin ${ }^{2}$, Yanwirasti ${ }^{1}$, Fedik A. Rantam ${ }^{3}$
}

${ }^{1}$ Department of Anatomy, Faculty of Medicine, Andalas University, Padang, Indonesia. ${ }^{2}$ Department of Histology, Faculty of Medicine, Andalas University, Padang, Indonesia. ${ }^{3}$ Stem Cell Research and Development Center, Universitas Airlangga, Surabay a, Indonesia. ${ }^{4}$ Department of Microbiology, Faculty of Veterinary Medicine, Universitas Airlangga, Surabaya, Indonesia.

*Corresponding author: gustirevillaelok@yahoo.com

\begin{abstract}
The therapy to heal the bum wound is still imperfect, therefore it is important to conduct specific research concerning this topic that benefits to society. Using both Bone Marrow-stem cell (BM-MSc) and peripheral blood mononuclear cells (PBMCs) from allogenic donors as part of the therapy to heal the bum wound seems to give positive prospect for the future treatment. In this experiment, PBMC and rat BM-derived from mesenchymal stem cell were used as the therapy model. lmmunocytochemistry was used as the method to characterize the phenotype of MSc, It was also used to express the collagen type I and the Indirect ELISA in analyzing the TGF. $\beta 1$ secretion. The rats with bum wound were divided into 2 kinds of group; the first group of rats was selected to control the use of PBS; while second group of rats was used as the treatment object that was medicated by the applying of the combination of both BM-MSC and PBMC. Stem-cells subcutaneously administered dose applied to each rat was around of 2 x 106 cells. The result showed that the levels of TGF- $\beta 1$ secretion in day 3rd and day 7 th on the rats which were treated by using the combination of BM-MSC and PBMC were higher compared to the rats from the control group. The experiment that concerns on the thickness of the collagen showed that combination between BM-MSC and PBMC stem cell make it possible in increasing the thickness of collagen 1, besides; it also showed significant differences $(\mathrm{p}=0.000)$. This research proved that the combination of BM-MSC and PBMC stem cell served can accelerate the healing process for the bum wound on rats through Increasing of TGF- $\beta 1$ secretion and collagen type 1 expression, It means that PBMCs can be applied as good as chemoattractant.
\end{abstract}

Key words: Wound healing, stem cell, allogenic, TGF-ß1, type 1 collagen.

\section{INTRODUCTION}

Burns is considered as one of the serious health problems; because it can cause physical damage and even death. Bums can appear as the effect of heat (thermal) chemical, electrical, and radiation. The damage is classified depend on the location, the depth and the size of the bum wound (Evers et al., 2010). The depth of the burn wound will identify the temperatures as well as the 
exposure duration of the heat. Based on their depth, bum wound is divided into three groups: first degree (superficial), second-degree (partial), and third• degree (full thickness). Each group shows the damage possibility that might affect the layers of epidermis and dermis. Serious wound that is caused by the heat will need a proper treatment to accelerate the healing process of the wound (Syamsuhidayat et al, 2003; Vern et al., 2001).

Healing the burn wound needs a complex process involving several interrelated stages such as: inflammatory, proliferative (granulation tissue formation, reepithellallization, extracellular matrix formation) and remodeling. The three phases of wound treatment will involve the interaction of several mediators, cells and extracellular matrix proteins (Kumar et al., 2004). The therapy toward the deep burn wound has been conducted in various ways such as skin grafts and administration of growth factors, but they have not showed satisfactory results. Now, researchers focus on the use of stem cells as part of the treatment in various diseases including burn wound (Metcalfe et al., 2007).

PBMCs stem cells are hematopoietic cells that consist of monocytes, fibrocytes, and ephithelial progenitor cell (EPC). Monocytes and fibrocytes have specific character as antigent precenting cell (APC) that produce the cytokines and the growth factors which are important during the process of inflammation and formation on collagen (Abe et al., 2001). Meanwhile, BMMSC is a non hematopoeitic cells that is characterized as multi-potent progenitor which is able to differentiate the chondrocytes, osteoblast, fibroblast, epithelial cells, and neuron cells (Pittenger et al., 1999; Liu et al., 2009). Both PBMC and BM-MSC stem cells expressed similar chemokines and receptors such as SLC/CCR7, SDF-1 $\alpha$ and CXCR4 (Sasaki et al., 2008) so it makes the stem cells capable in migrating to the damaged tissues. PBMC and BM-MSC stem cells can differentiate the cells that are needed for refinement of the skin, such as fibroblast, keratinocytes and endothelial cells (Abe et al., 2001; Hedrick et al., 2010; Medina et al., 2000; Dan Sasaki et al., 2008. In the previous study, it showed that the combination of Hematopoetic stem cells (HSC) and BMMSC from human which were induced to mice that previously used to see the growth of bones can possibly cooperate in forming bone tissues; it also enhanced the number and the diameters of blood vessels (Moioli et al., 2008). Based on previous study and the ability of PBMCs and BM-MSC stem cells that were able to differentiate the existing skin cells, then it is necessary to conduct a study to see the further effect that possibly appear as the result for the combination used of both PBMCs and BM-MSC on TGF- J3 1 secretion and type I collagen expression as variable to analyze of healing process in bum wound 


\section{MATERIALS AND METHODS}

Peripheral Blood Mononuclear Cell (PBMC) Isolation

Peripheral blood mononuclear cells (PBMCs) used for the research were taken from Wistar rat that were anesthetized with Xylazine and Ketamine (1: 1). The blood taken $(3.5 \mathrm{ml})$ from the rat tail was then added with $3.5 \mathrm{ml}$ sterile PBS: the mixture of blood and sterile PBS was then added to the centrifuge tube which was filled with $3.5 \mathrm{ml}$ ficoll histopaque density 0.177 . The mixture was centrifuged for 30 minutes on $1600 \mathrm{rpm}$ which then crated the Buffy coat. Next,

Bone Marrow Mesenchymal Stem Cells

Mesenchymal stem cells were derived from bone marrow of the rats. Rats BM-MSC that are used in this research were gotten from Stem Cell Laboratory, Institute of Tropical Disease (ITD) Airlangga University Surabaya. Prior to be

\section{Experimental to Animal's Burn}

The Wistar rats that were used in this research were divided into 2 groups. Group 1 served as the control group while group 2 was treated by using the combination of BM-MSC and PBMCs scale 1:1. Burn making on rats were applied by using method from (Paramonov D. and Cheboterevcit Shuid et al., 2008) method. Rats were anesthetized with xylazin and ketamine (ratio $1: 1)$, then the fur of the rats were sheared. To make a thick bum mark on the rats, the plate was heated on boiling water for 30 minutes the Buffy coat was added with sterile PBS $5 \mathrm{ml}$ and then centrifuged for 5 minutes on $1600 \mathrm{rpm}$ to separate the supernatant. This re suspension was conducted for 2 times to take the granules which were then added with PBS; then the cells could be counted by using hematocytometer. From the result, the number of PBMC was recognized from the sample was $3 \times 10^{7}$. But the PBMCs used in this research was $1 \times 10^{6}$ cells $/ \mathrm{ml}$.

used, the MSC in monolayer tube petridish would be separated, so the number of cells which will be used for this research can be counted. The number of BM-MSCs cells that are equal for 1 rat is $1 \times 106$ cells $/ \mathrm{ml}$.

which is then sticks to the back of the rats for 20 minutes. After the bum making procedure the PBS was injected to the control group; while the combination of BM-MSC and PBMCs was injected into the treatment group. The burn wounds were wrapped by using tegaderm film and gauze elastomull haft; antalgin as an analgesic was also injected to the rat. On the 3rd and 7th day, the blood was taken via intracardiac to measure the growth factor of TGF$\beta 1$ from serum and collagen type 1 of the tissue. 
Indirect ELISA TGF. $\beta$ Examination

Enzyme-Linked Immuno Sorbent Assay (ELISA) was used to analyze TGF- $\beta 1(\mathrm{R} \& \mathrm{D})$ as it is performed in manufacturer's manual instructions. Blood was taken and then centrifuged to obtain the serum which was then put on the plate and added with 50ml assay (blank, standard, and sample). The plate was placed on shaker that

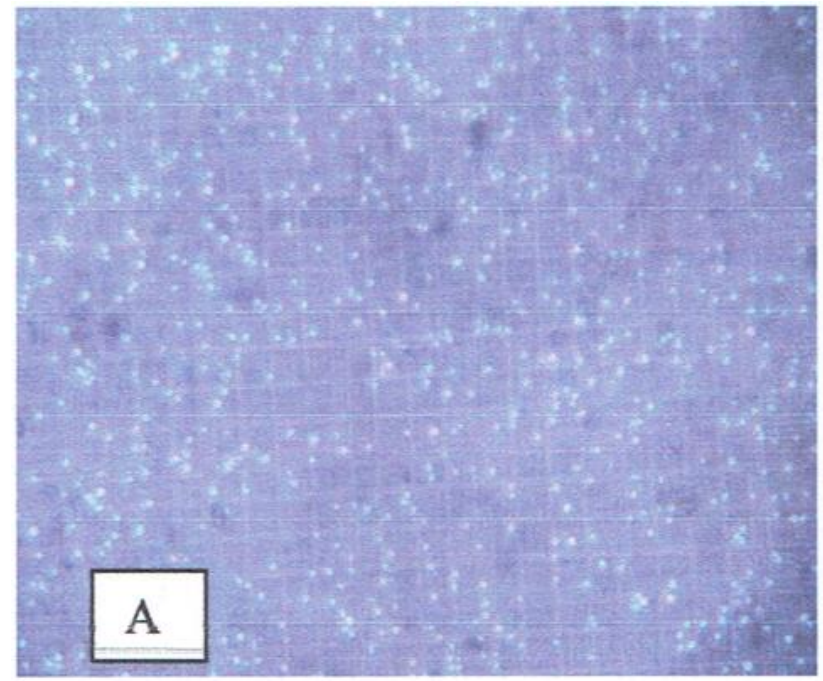

Figure 1. A. Purified PBMC isolated from whole blood after the separation process by using ficoll histopaque 1.077 (sigma). B. Monolayer of MSC was developed on rat bone marrow derived mesenchymal stem cell after the culturing by using Dulbecco's Modified Eagles Medium (DMEM).

$100 \mathrm{ml}$ enzyme conjugate into the plate except for the blank (filled with $100 \mathrm{ml}$ washing buffer), and incubating the plate for 2 hours on room temperature. After incubation, $100 \mathrm{~mL}$ substrate solution (made of color reagent A and B mixed just do this step) was added into each plate, the next incubating process that was held for 30 minutes in the dark room with normal temperature will create a blue skies color.

\section{Immunohistochemistry Collagen Type 1}

The preparations were de-parafinisation by dipping it into xylol 3 for times; it was then rehydrated, by using xylol, which was then

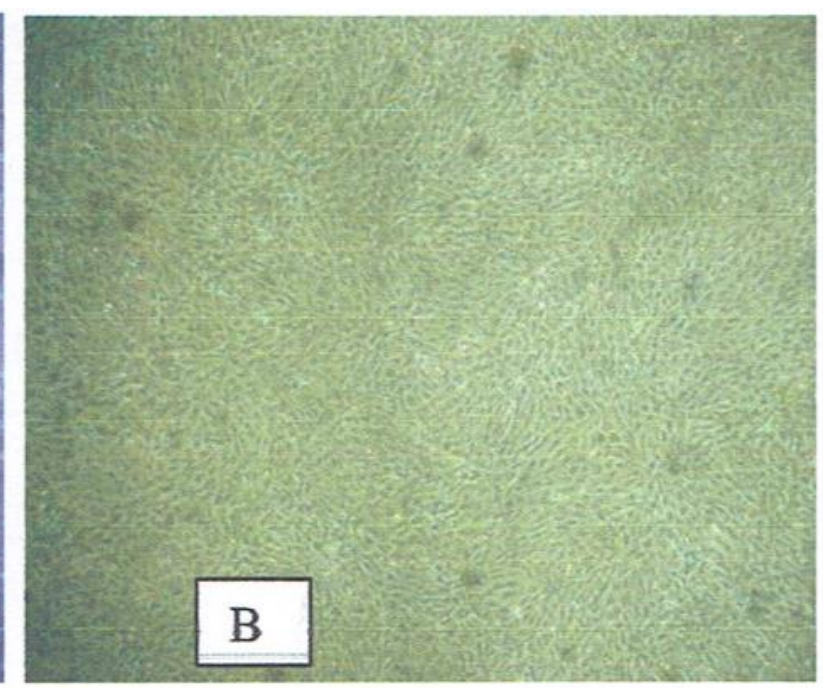

is driven with $50 \mathrm{rpm}$ speed for 3-5 minutes, and then incubated for 2 hours in a normal room temperature. After incubation, the plate was then washed by using washing buffer $300 \mathrm{ml} I$ and then shacked for 2 more minutes at 50-100 rpm speed. The further procedures was adding the 
$\mathrm{H}_{2} \mathrm{O}_{2}$ and then in methanol for 5 minutes; the slides were then rinsed with distilled water and PBS for 3 times. The cleaned slides were put in anti collagen 1(mouse anti-rat 1:50) for 30 minutes on room temperature and then rinsed with PBS 3 times, each process is done for 2 minutes. The daubed tissues were marked with Pap pen. Slides were then incorporated on the secondary antibody (Rabbit anti-mouse antibody biotinylated label) for 30 minutes and rinsed with PBS solution 3 times; similar with the previous procedure, the rinsed process with PBS Solution was done for 2 minutes. Put the slides into streptavidin HRP labeled for 30 minutes, then rinsed in a solution of PBS 3 times, each of them was also done for 2 minutes. Put slides into the substrate chromogen for 3-10 minutes, and rinse with a solution of PBS for 2 minutes that needs to be repeated 3 times and finally it need to be rinsed with aquadestilata. After that, the slides were put into Mayer haematoxylin for 6-15 minutes; to end the process we need to rinse the slide with running water and mounting. Microscope was used to measure the thickness of the collagen type 1 after immunohistochemical staining.

\section{RESULT}

After the stages of isolation from PBMCs and BM-MSC stem cells, the obtained results are shown in figure 1.

Transforming Growth Factor- $\beta 1$ (TGF- $\beta 1$ ) Secretion.

Levels of growth factor of TGF- $\beta 1$ secretion in the serum after adding the PBS (Control), PBMC, MSC and combination of BM-MSC and PBMCs on the rats with the full-thickness of bum wound is continuously calculated on days 3rd and 7 th.

Based on Figure 2, it showed that on 3rd and 7 th day; the average levels of secretion growth factors of TGF- $\beta 1$ after the PBMC and combination of both BM-MSC and PBMCs on the treatment rats were higher than the control group, while the group was given BM-MSC the levels of TGF- $\beta$ decreased. Statistically, the average level 


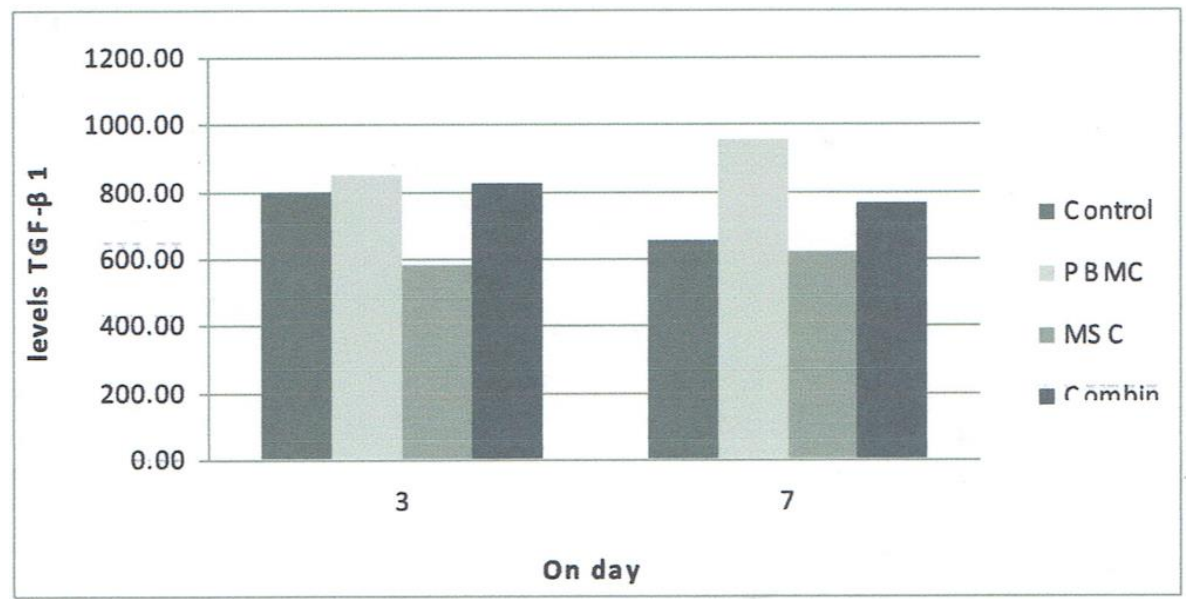

Figure 2. The graph of average levels growth factors TGF- $\beta 1$ secretion with full thickness burn on the controlled rats and the treatment rats which got medication by using the PBMC, MSC and combination of BM-MSC and PBMCs calculated on day $3^{\text {rd }}$ and $7^{\text {th }}$

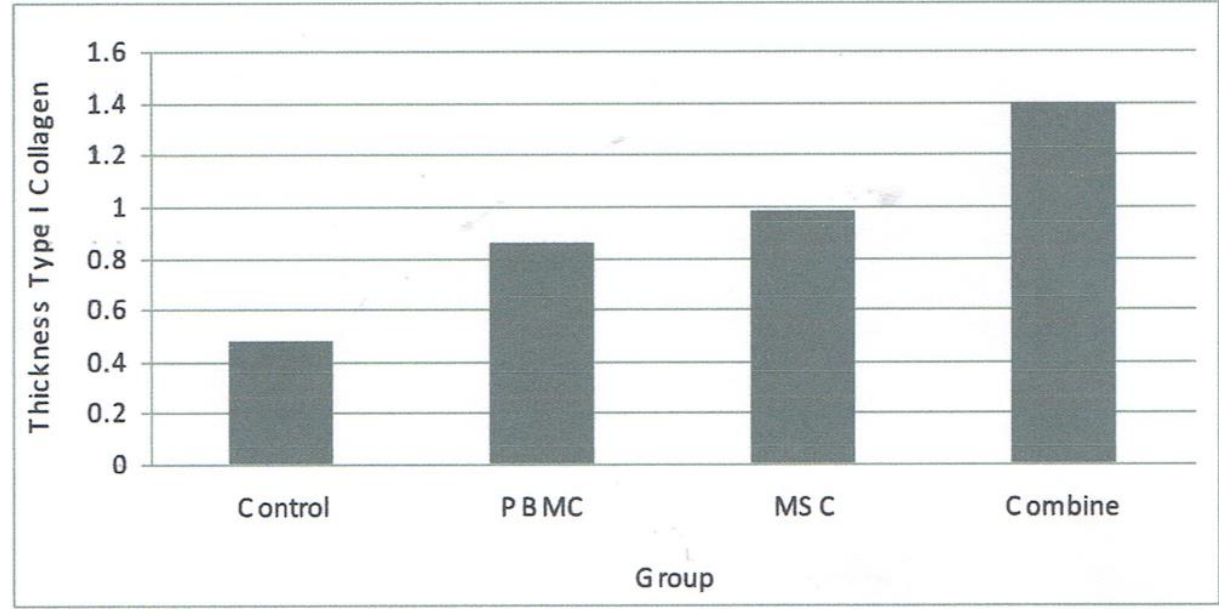

Figure 3. The graph of average thickness on the collagen type 1 with full thickness burn wound in rats in both control, PBMC, MSC and combine group rats calculation on day 14.

Of this secretion showed on $3^{\text {rd }}$ and $7^{\text {th }}$ day significant difference $(\mathrm{p}=0.003$ and $\mathrm{p}=0.008)$.

\section{Collagen Type 1 Expression}

Immunohistochemical examination toward the expression of collagen performed on day 14 th by calculating the thickness of the collagen type which gave positive reaction to anti collagen 1 on rat's tissue skin bums. In each group, rat's tissue skin burn was observed and measured; the thickness of the collagen was seen by using microscope which is connected to the computer screen.

In Figure 3, it shows that the average thickness of the collagen type 1 in rat's tissue skin bums on the treatment group PBMC (0.860), BM$\operatorname{MSC}(0.977)$ and combine group $(1.395 \mu)$, is higher than the control group $(0.475 \mu)$ which indicates the significant difference $(p=0.000)$. These circumstances showed that accelerate wound healing process were possible for the treatment group, but it 

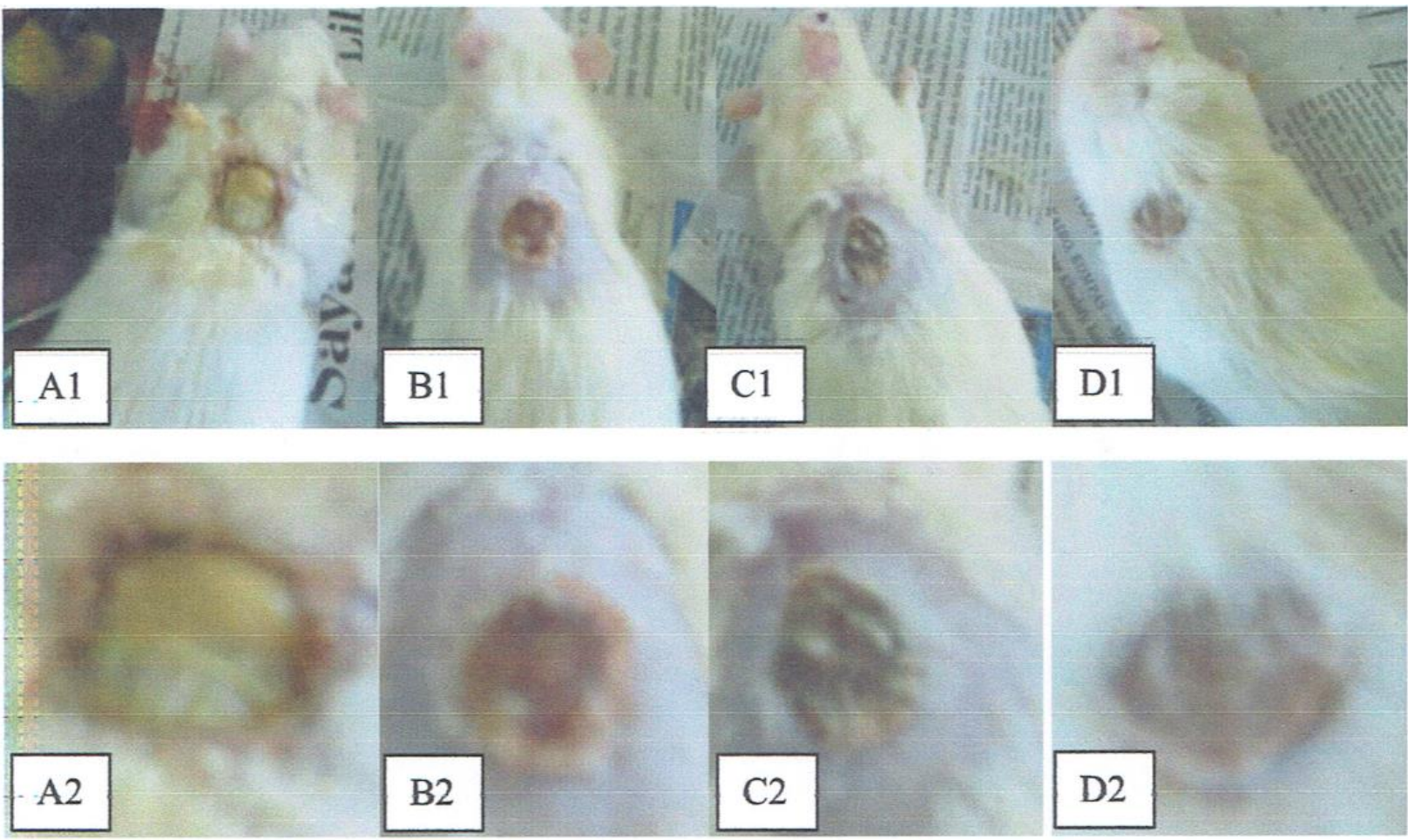

Figure 4. A1 and A2 Representative image of burn wounds control group on day $14^{\text {th }}$ showed that rat skin burn still has an infection,

$\mathrm{B} 1$ and $\mathrm{B} 2$ representative image of burn wounds PBMC group on day $14^{\text {th }}$ showed that rat skin burn still has an scar,

$\mathrm{C} 1$ and $\mathrm{C} 2$ Indicated that theraphy stem cell by using the BM-MSC significantly accelerated the wound closure with high heating possibility,

D1 and D2 Indicated that theraphy stem cell by using the combination of BM-MSC and PBMCs significantly accelerated the wound closure with high healing possibility.

might less possible for the control group as it is seen in figure 4.

The thickness of collagen fibers on the control group and the combine group after the immunohistochemical examination toward the tissue skin bums on rats can be seen in Figures 5. It showed that the control group rats given solvents and combine group on rat skin tissue bums. After analyzing the IHC, it shows that the expression of type collagen fibers on the control group only has a shadow of a thin brownish color (400x). While the treatment group showed the positive dark brown. The healing process toward the bum wound on the treatment rats showed the significant difference compared to the controlled group as it is seen in the expression of type 1 collagen fibers on the 14th day, where the fibers were more visible.

\section{DISCUSSION}

This research examined the process of repairing and accelerating the bum wound by applying the therapy that used the combination of stem cell BM-MSC and PBMCs, such as the secretion of growth factors and the expression levels of collagen type I. The result indicates that the stem cell therapy or exogenous/allotransplantasi was proven to accelerate the healing process of bums wound on rats. TGF- $\beta 1$ is classifies as a multifunctional growth factor that plays an 
important role in every phases of the wound treatment; because the secretion of TGF- $\beta 1$ levels will increase during tissue damage.

The results showed that the secretion of TGF$\beta 1$ levels on the stem cells that were combined with BM-MSC and PBMC will increase, while the controls group showed no significant. The increasing levels of TGF- $\beta 1$ secretion occurred because PBMCs are hematopoietic cells that consist of monocytes, fibroytes and EPC Fibroytes and monocytes can be used as APC that produced the cytokines: so the growth factor makes BM-MSC capable in differentiating the cell types. Both stem cells also express the chemokine with the same receptors namely SLC/CCR7, SDF-1 $\alpha$ and CXCR4 (Sasaki et al.,

2008). The increasing level of TGF- $\beta$ accelerated the migration of both stem cells; it also increased the number of proliferation cell.

This situation showed that both of the testedstem cells provided the synergistic effect on bum wound; it showed that the BM-MSC did not give an affect to PBMCs. The result of this research was also supported by the previous study, it was said that the combination of Hematopoietic stem cells (HSC) and BM-MSC from human which is then induced to mice to see the growth of bones can also cooperate to form the bone tissues and enhance the number and diameters of blood vessels (Moioli et al., 2008).
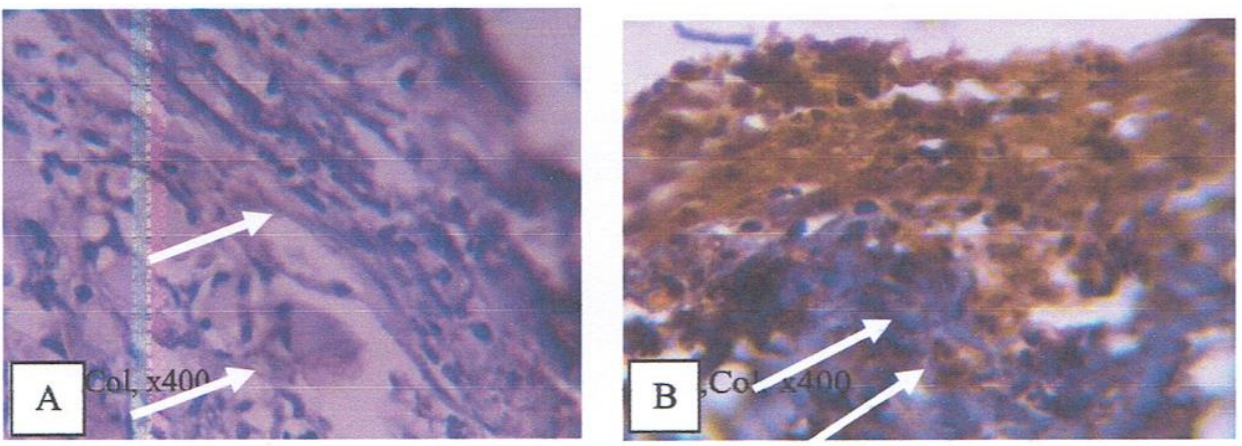

Figure 5. Staining IHC Type 1 Collagen Fibers on Staining Positive Control Group(A) and Combine BM-MSC and PBMCs(B)

The increasing secretion of TGF- $\beta 1$ after the PBMCs step can accelerate the healing process of bum wound by affecting the migration of inflammatory cells, endothelial cells, regulate cell growth and differentiation of keratinocytes. The role of TGF- $\beta 1$ on the regulation of cell growth is to stimulate the process of epithelial mesenchymal transition (EMT). TGF- $\beta 1$ binds to receptors type 1 and II through the activation of receptor tyrosine kinase (RTK). Activation of these receptors would lead to phosphorylation of
Smad 2 and Smad 3, Smad 2 and Smad 3 that bind to Smad 4 as co-activator.Bond Smad 2, Smad 3 with Smad 4 will be transferred to the nucleus to bind to the DNA binding protein which would stimulate the inhibit transcription of genes that influence the occurrence of EMT. Collage is a component of the extracellular matrix which is produced by fibroblasts. Active fibroblasts is a type1 collagen mRNA that subsequently will form collagen type I. The increasing thickness of collagen type 1 after the 
injection of BM-MSC to the treatment group showed the significant different compared to the control group. The increasing thickness occurred due to the use of BM-MSCs to produce mediators that have paracrine effect to increase the amount of fibroblast migration in wound tissue (Smith et al., 2010). The PBMCs that contained fibrocytes produced the type Icollagen which was influenced by the inflammatory cytokines IL-1 and TGF- $\beta 1$ (Abe et al., 2001). On bums wound, the number of fibrocyte increased two times greater than in normal conditions (Yang et al., 2001). BM-MSCs were used to differentiate the fibroblasts via the Wnt I 13catenin (Liu et al., 2009). Fibroblasts migrated to the wound as an effect of TGF-13, CTGF and monocyte chemoatractan protein-1 (MCP-1) as mediators that stimulated the fibroblasts to produce collagen type 1 . BM MSC also helped wound contraction on vivo, because these stem cells in vitro showed contractile phenotype,the expression of a smooth muscle action/ miofibroblast marker, and this expression of myofibroblast marker affected the wound contraction (Lau et al., 2009; Smith et al., 2010). This situation showed that both tested-stem cells provide synergistic effect.

The increasing thickness of collagen affected the wound healing phases especially on the inflammatory phase, proliferation, and remodeling. Collagen in the inflammatory phase helped monocyte cells to migrate from peripheral blood to extra-vascular to perform its functions as phagocytosis (Newman and Tucci, 1990). In the proliferative phase, collagen was use a as an instrument in granulation tissue formation and wound strength (Yang et al., 1999). It accelerated the closure of the burns wound; the thickening process of the type 1 collagen on immunohistochemical staining appeared after the process of adding combine PBMCs and BMMSC, which can be seen in Figure5B. In the remodeling phase; synthesis and degradation of collagen play a necessary part to accelerate the wound healing process. In this phase, BM-MSC regulate collagen deposition and MMP I TMMP in order to increase strength and integrity of the scar tissue (Maxon et al., 2012).

Even so, the effect of combining the steam cell on other growth factors and matrix extracellular has not been carried out. For that reason, further research to investigate the influence of using combined PBMCs and BM-MSC stem cells on growth factors such as FGF, VEGF and PDGF and fibronectin and laminin needs to be developed. 


\section{REFERENCES}

Abe R,Donnely SC, Peng T,Bucala R, Metz CN. 2001. Peripheral blood fibrocytes: differentiation pathway and migration to wound sites. J. lmmunol. (166): pp. 7556-62.

Evers LH, Bhavar D, Mallander P. 2010. The biology of bum injury. Experi. Dermatol. (19): pp. 777-783.

Herdrich BJ, Lind RC, Liechty KW. 2008. REVIEW Multi potent adult progenitor cells: their role in wound healing and the treatment of dermal wounds. Cytotherapy10 (6): pp. 543-550.

Kumar S, Peng FW, David JL. 2004. What is new in wound healing. Turkish J. Med. Sci. (34): pp. 147-160.

Lau K, Paus R, Tiede S, Oay P, Bayat A. 2009. Exploring the role of stem cells in cutaneous wound healing. Experi. Dermatol. (18): pp. 921-933.

Liu ZJ, Zhuge Y, Velazquez OC. 2008. Trafficking and differentiation of mesenchymal stem cells. J. Cellul. Biochem. (106): pp. 984-991.

Maxson S,Lopez EA, Yoo D, Miagkova AD, Leroux MA. 2012. Concise Review: Role of mesenchymal stem cells in wound repair. Stem cells translation medicine; (1): pp. 142-149.

Medina A, Erin B, Nicholas C, Aziz G. 2009. Circulating monocytes have the capacity to be trans-differentiated into keratinocyte-like cells. Wound repair and regeneration 17 , pp. $268-277$ by the Wound Healing Society.

Metcalfe AD, Ferguson MWJ. 2007. Tissue engineering of replacement skin: the crossroads of biomaterials, wound healing, embryonic development, stem cells and regeneration. J. Royal Soc. Interface. (4): pp. 413-437.

Moioli EK, Clark PA, Chen M, Dennis JE, Erickson HP, Gerson SL and Mao JJ. 2008. Synergistic actions of hematopoietic and mesenchymal stem/progenitor cells in vascularizing Bioengineered Tissues. Plos One 3 (12): pp.1-11.

Newman SL, Tucci MA. 1990. Regulation of human monocyte/macrophage function by extracellular matrix adherence of monocytes to collagen matrices enhances phagocytosis of opsonized bacteria by activation of complement receptors and enhancement of $\mathrm{Fc}$ receptor function. J. Clin. Investig. 86, pp. 703-714.

Pittenger MF, Mackay AM, Beck SC, Jaiswal RK, Douglas R, Mosca JD, Moorman MA, Simonetti OW, Craig S, Marshak OR. 1999. Multi-lineage potential of adult human mesenchymal stem cells. Science (284): pp. 143--147.

Sasaki M, R Abe, Y Fujita, S Ando,D lnokuma, Hiroshi Shimizu. 2008. Mesenchymal stem cells are recruited into skin cell type repair by trans-differentiation into multiple wounded skin and contribute to 
wound. J. lmmunol. 2008; (180): pp. 2581-2587.

Smith AN, Willis E, Chan VT, Muffley LA, lsik FF,Gibran NS, Hocking AM. 2010. Mesenchymal stem cells induce dermal fibroblast responses to injury Experimental Cell Research. January 1; 316(1): pp. 48-54.

Syamsuhidayat R. 1997. Buku ajar ilmu bedah. Edisi Revisi, Penerbit Buku Kedokteran EGC.Jakarta Vem AK, BA Latense. 2001. Specimen collection and analysis bum wound. Methods in molecular medicine wound healing. Edited by Luisa D \& Aime LB. 78. Human Press Inc.

Totowa NJ, Yang L, Chan T, Demare J, lwashina T, Ghahary A, Scott PG, Tredget EE. 2001. Healing of Bum Wounds in Transgenic Mice Overexpressing Transforming Growth Factor- $\beta 1$ in the Epidermis. Ameri. J. Pathol. 159 (6), Yang L, Qiu ex, Ludlow A Ferguson MWJ, Brunner. 1999. Technical advance active transforming growth factor-b in wound repair determination using a new assay. Am. J. Pathol. (154): pp. 10\&-111. 